\title{
Development of a Dust Measurement System
}

\author{
T. Ewetumo ${ }^{1}$, A. O. Oke ${ }^{2, *}$ and J. C. Ehiabhili ${ }^{3}$ \\ ${ }^{1}$ Federal University of Technology, Akure (FUTA) \\ Department of Physics, FUTA (Akure, Nigeria) \\ ${ }^{2}$ Federal University Oye-Ekiti (FUOYE) \\ Department of Physics, FUOYE (Oye-Ekiti, Nigeria) \\ ${ }^{3}$ Federal University Oye-Ekiti (FUOYE) \\ Department of Physics, FUOYE (Oye-Ekiti, Nigeria) \\ *Corresponding author's email: aduragbemi.oke [AT] fuoye.edu.ng
}

\begin{abstract}
Dust particle are particulate matter that can become suspended in the atmosphere and deposited. Dust is present in the atmosphere has significant effect climate, health of human, and strong influence on the solar energy during dry season. The dust monitoring device developed consists of sharp dust sensor module that has capacity of measuring particle size about PM2.5 and above, microcontroller (arduino mega 2560), micro secure data (MicroSD) shield card, with intelligent liquid crystal display unit $(L C D)$ and all are link together to form the complete unit. The dust measuring system compare with available dust device has the correlation of 0.999980 and maximum value of $0.541 \mathrm{mg} / \mathrm{m}^{3}$. Also the sensitivity, resolution and error are $5 \mathrm{~V} / 0.1 \mathrm{mg} / \mathrm{m}^{3}, 0.001 \mathrm{mg} / \mathrm{m}^{3}$ and $\pm 0.005 \%$ respectively, at $67 \%$ relative humidity and temperature of $32^{\circ} \mathrm{C}$. The total power consumption of the dust monitoring system is $1.06 \mathrm{~W}$.
\end{abstract}

Keywords - Dust, particle, sensor, optical, microSD card, LCD, arduino.

\section{INTRODUCTION}

The word dust describes fine particles that travel around in the atmosphere. The atmosphere is made up many constituents called aerosol of which dust particle is included. This dust is formed when fine particles are being blown and carried by the action of the force often called wind. Dust emanates from different sources - indoor and outdoor. Some dust sources are from vegetation (pollen and fungi), sea salt, fossil fuel combustion, burning of biomass industrial activities, drilling, and blasting, excavating, loading and tipping, transporting, crushing, untarred road, cleaning and maintaining fixed and mobile plant. Road generated dust by traveling vehicles contribute to the release of particulate matter in the atmosphere. (Thongplang, 2015).

Often times, in this part of the world, dust particles settle in houses and house materials, offices and office materials. There are two main season in Africa - the wet and the dry season. In Nigeria, there is a variance between the northern part and the southern part of the country in terms of season in the year. The north experiences a long dry season and a very short rainy season. Sometimes, rain fall in north in four months or less. But the south has a longer wet season. The rainfall may be up to eight months in the year. And so the rate of dust particles in these regions varies. The effect accompanied in the dry season sometimes called harmattan is the same in the regions.

The control of road dust has been a significant challenge in urban areas, and also in places with high level of vehicular traffic on untired roads. Justifiably, a good number of African countries still fall victim of the control of dust especially in industrial areas. The harmattan season is accompanied by the intense heat from the sun. This dries up the sand and makes it easier for wind to carry the dust particles around in the atmosphere by a conductive force. Besides the dust particle in industrial areas which has effect on the health of human around the working environment, harmattan season is the major period when mostly everybody in this part of the world suffers from the exposure to dust (Chineke and Chiemeka, 2009).

\section{CLASSIFICATION OF PARTICLE}

Classifications of particles are in accordance with its aerodynamics diameter. Particle is usually categorized under two sizes - smaller than $10 \mu \mathrm{m}$ (particle matter (PM) 10) and smaller than $2.5 \mu \mathrm{m}$ (PM 2.5) because the measurement of particle shapes are difficult to measure. The size of the particle is defined by matching the gravitational settling velocity of a particle with a perfect sphere of a $1 \mathrm{~g} / \mathrm{cm}^{3}$ density. This will make particle have different shapes and densities 
because of different sphere sizes. An ideal sphere was chosen to limit the complexity of particles taking it to be homogeneous sphere having an ideal aerodynamics diameter which is the permissible (Geiling et al., 2011). World Health Organization (WHO) and United State of America (USA) Environmental Protection Agency (EPA) opined that particles affect more people worldwide than any other pollutant.

\section{HAZARD EFFECTS OF DUST PARTICLES}

Dust particles with smaller densities have the propensity to stay longer and travel in the air as compared with particles with bigger densities. The particles may be inhaled through the mouth and nose easily which if left uncheck may pose serious public health hazard; increasing breathing problem; damaging lung tissue. Dust particle can reduce visibility and hamper road safety. Work activities like construction, building, demolition, quarry and maintaining services generates respirable dust particle. Inhalation of respirable dust particle is known to cause a disease called silicosis and cancer and it is thought to contribute to a condition known as chronic obstructive pulmonary disease (Thongplang 2015; Peter, 2011; Technical fact sheet, 2010).

\section{METHODOLOGY}

The Sharp dust sensor uses electro-optical sensing method to detect the presence of dust. A light detector (photodiode) detects a deflected light by light emitter diode. The amount of light deflected correspond to the density of dust. Equation 1 relates the relationship between light transmission and the dust concentration $c$ according to LambertBeer's law (Mokhloss, 2012).

$$
I=I_{0} \cdot e^{-\varepsilon \cdot c \cdot l}
$$

Where:

$I_{0}=$ initial intensity

$I=$ resulting intensity of the light beam

$\varepsilon=$ coefficient of extinction (a specific constant accounting for dust type and application)

$l=$ distance

$c=$ dust concentration

\subsection{Instrument Development}

The sharp dust sensor module has six (6) connector pins. Figure 1 shows the internal circuit diagram of Sharp dust sensor. The Pin 5 ( Vo) produces a voltage that is equal to the amount of dust particles passing through the hole. The pin 5 was connected to an arduino microcontroller with a micro Secure Data (SD) card shield and liquid crystal display (LCD) screen for processing, storage and LCD display magnitude of dust density respectively. The arduino was programmed to link the LCD and store the dust density to be collected using C programming language. The output pin of the Sharp dust sensor $(\mathrm{Vo})$ was connected to one of the analog pin of the arduino microcontroller.

A $9 \mathrm{~V}$ rechargeable battery and power supply was designed for the system with a power switch to control when it is $\mathrm{ON}$ and OFF. The designed power supply was connected to the Vin of the arduino mega 2560 to power the arduino. The Vin of the arduino mega 2560 was designed to handle voltages between $7 \mathrm{~V}$ and $12 \mathrm{~V}$. The Sharp dust sensor and LCD was powered via the $5 \mathrm{~V}$ power section of the arduino. The dust sensor is housed in black case to shield the sensor from humidity, radiation and temperature. A 7 inch plastics rod which was used to raise the sensor above the case containing all other circuit component as shown in Figure 2. The plastic case houses the arduino mega 2560 microcontroller, LCD microSD shield, rechargeable battery and power switch. The dust optical sensor is positioned outside at that height for proper exposure to air around the environment.

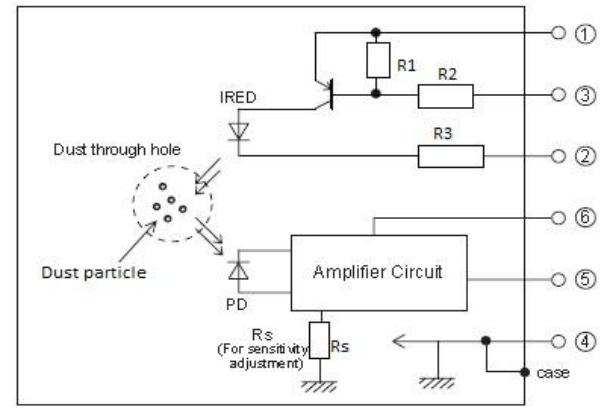

Figure 1: Internal circuitry of Sharp dust sensor

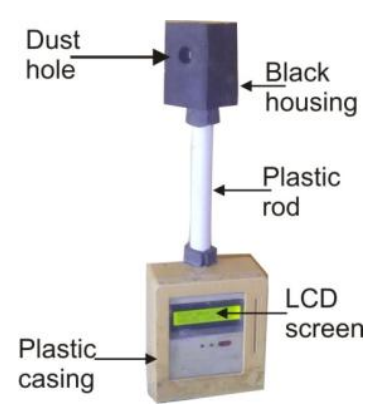

Figure 2: Dust measurement device 


\subsection{Test and Calibration of the Instrument}

The Dust Instrument was tested for response by blowing the dust towards the sensing point of the sensor and the value displayed on the LCD screen increases as the blowing speed increase and vice versa. The dust measuring instrument was calibrated using the sensitivity of a known sensor $\left(0.5 \mathrm{~V} / 0.1 \mathrm{mg} / \mathrm{m}^{3}\right)$. The output voltage ranges from $0.9 \mathrm{~V}$ without dust $\left(0 \mathrm{mg} / \mathrm{m}^{3}\right)$ to $3.2 \mathrm{~V}$ at maximum of $0.541 \mathrm{mg} / \mathrm{m}^{3}$. Using arduino ADC $0-5 \mathrm{~V}$, Vin $-0.9=0$;

$$
\begin{gathered}
\text { dust density }=\frac{(\text { Vin }-0.9) \mathrm{V}}{\text { sensitivity }} \\
\text { dust density }=\frac{(\text { Vin }-0.9) \mathrm{V}}{0.5 \mathrm{~V} / 0.1 \mathrm{mg} / \mathrm{m}^{3}}=\left(\frac{(\text { Vin }-0.9)}{5}\right) \frac{\mathrm{mg}}{\mathrm{m}^{3}}=0.2 \mathrm{Vin}-0.18
\end{gathered}
$$

The dust measuring instrument built was compared with commercially available dust instrument (Dust Particle Measuring Device PCE-MPC10). The result of the measurement obtained is shown on table 1 and figure 3 shows the graph of comparison between the two dust instruments. The graph follows the same trend and the correlation obtained was 0.999980 which shows good agreement and performance of the dust measuring device is up to standard. At temperature $32^{\circ} \mathrm{C}$ and relative humidity $65 \%$, error estimated was $\pm 0.005 \%$. The resolution is $0.001 \mathrm{mg} / \mathrm{m}^{3}$. The range of measurement is between 0 to $0.541 \mathrm{mg} / \mathrm{m}^{3}$. (Application note of Sharp Dust Sensor).

The dust density equation was computed on the arduino sketch using $\mathrm{C}$ programming language. The $\mathrm{mg} / \mathrm{m}^{3}$ value was multiplied by 1000 for conversion to $\mu \mathrm{g} / \mathrm{m}^{3}$. The dust density was programmed to be displayed on the LCD and at the same time stored on the microSD card every one minute interval.

Table 1: Dust density comparison measurement between developed instrument and Dust Particle Measuring Device

\begin{tabular}{|c|c|c|}
\hline Time (mins) & Developed instrument $\left(\mu \mathrm{g} / \mathrm{m}^{3}\right)$ & PCE-MPC10 $\left(\mu \mathrm{g} / \mathrm{m}^{3}\right)$ \\
\hline 1 & 51.9143 & 51.90 \\
\hline 2 & 42.8134 & 42.77 \\
\hline 3 & 88.4507 & 88.43 \\
\hline 4 & 64.3555 & 64.36 \\
\hline 5 & 60.2051 & 60.21 \\
\hline 6 & 59.3750 & 59.38 \\
\hline 7 & 49.4141 & 49.41 \\
\hline 8 & 58.5449 & 58.54 \\
\hline 9 & 57.7248 & 57.71 \\
\hline 10 & 55.2246 & 55.22 \\
\hline 11 & 48.5484 & 48.58 \\
\hline 12 & 61.0352 & 61.04 \\
\hline 13 & 57.7248 & 57.71 \\
\hline 14 & 49.4042 & 49.41 \\
\hline 15 & 56.8778 & 56.88 \\
\hline 16 & 66.0156 & 66.02 \\
\hline 17 & 46.0938 & 46.09 \\
\hline 18 & 41.9534 & 41.94 \\
\hline 19 & 59.3750 & 59.38 \\
\hline 20 & 62.8953 & 62.70 \\
\hline 21 & 47.8639 & 47.75 \\
\hline 22 & 49.4042 & 49.41 \\
\hline 23 & 52.8344 & 52.73 \\
\hline 24 & 50.3441 & 50.24 \\
\hline 25 & 65.1879 & 65.19 \\
\hline 26 & 61.1352 & 61.04 \\
\hline 27 & 56.1047 & 56.05 \\
\hline
\end{tabular}
PCE-MPC10 


\begin{tabular}{|l|c|c|}
\hline 28 & 71.8262 & 71.83 \\
\hline 29 & 56.2547 & 56.05 \\
\hline & & 0.999980 \\
\hline
\end{tabular}

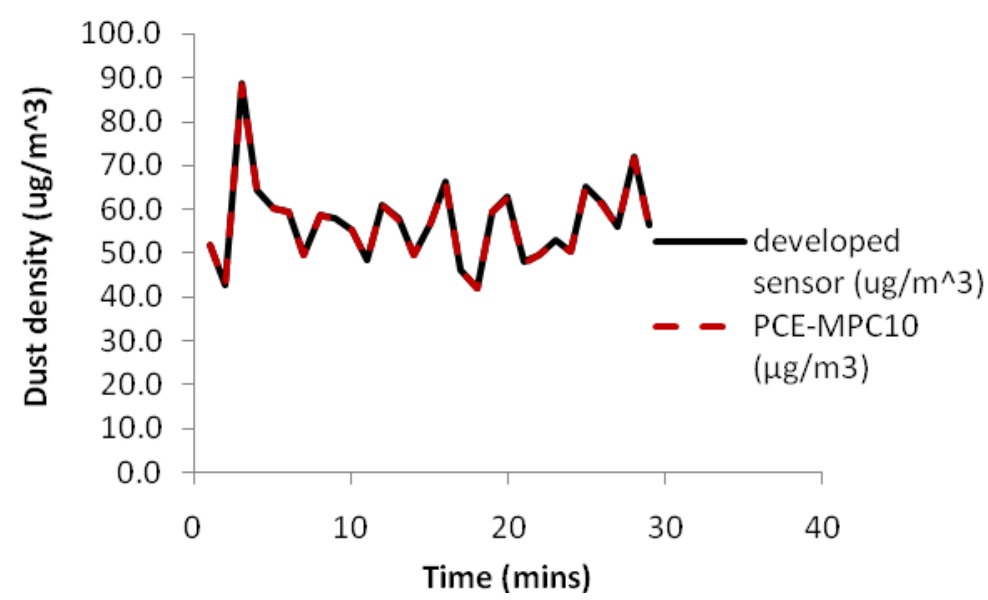

Figure 3: Correlation graph of the developed sensor

\section{RESULT AND DISCUSSION}

The dust instrument examination performance was carried out. It was found that the dust instrument measured from 0 to $0.541 \mathrm{mg} / \mathrm{m}^{3}$ with resolution of $0.001 \mathrm{mg} / \mathrm{m}^{3}$. It has minima error of $\pm 0.005 \%$ and when compared with other dust instrument, the correlation is 0.999980 which is closed to unity and response time is $0.1 \mu \mathrm{s}$ that is fast logging system. Also, the dust instrument was used to carryout measurement at various location and the results shows positively safe area and are that needed improvement to reduce dust effect on the habitant in the near future. See figures 4 and 5.

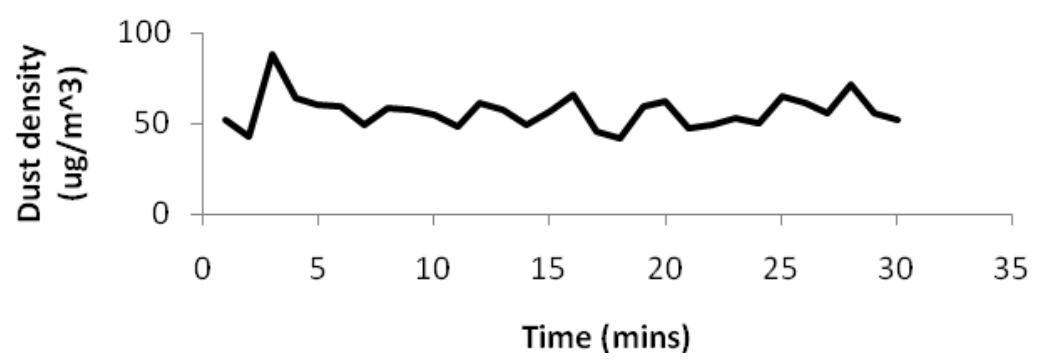

Figure 4: The graph of dust density of a room at Oye-Ekiti 13th October 2017, 7.30pm to 8:0pm

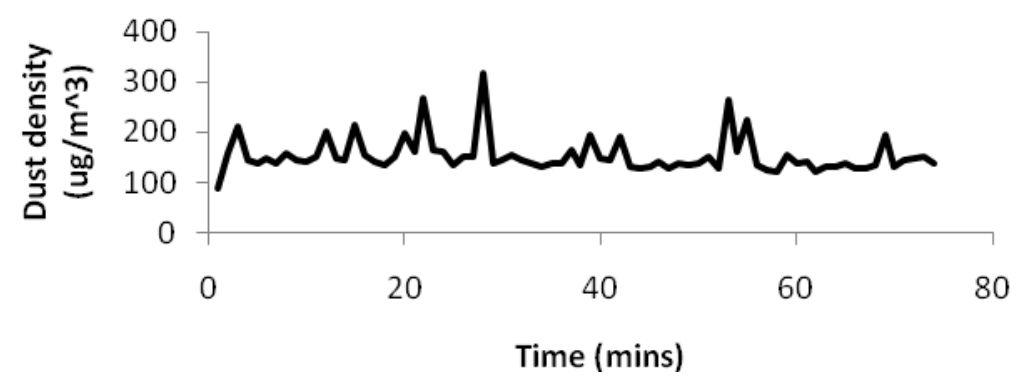

Figure 5: The graph of dust density taking in a vehicle Ibadan to Ife, 5th November 2017. 1pm to 2.30pm 


\section{CONCLUSION}

The dust instrument shows good response, and the performance was excellent compared with commercially available dust instrument. The range is from 0 to $0.541 \mathrm{mg} / \mathrm{m}^{3}$ with resolution of $0.001 \mathrm{mg} / \mathrm{m}^{3}$ and percentage error is $\pm 0.005 \%$. The dust instrument is cheap, easy to service and repair if malfunction.

The performance evaluation of the dust instrument showed that it can be used to carry out continuous measurement for dust monitory to study the effect of dust on the communication signals. Also, to see the effect of dust deposit on solar panel surface with time and its effect on the health of human being around quarry and dust producing environment.

\section{ACKNOWLEDGEMENT}

I acknowledge the assistance rendered by Dr. Ewetumo T. in the development stage of the research and throughout the manuscript typesetting and editing. The assistance rendered by Mr. Ehiabhili J.C. in data analysis and review of the manuscript is appreciated.

\section{REFERENCES}

[1] Application note of Sharp Dust Sensor GP2Y1010AU0F. www.google.com. Retrieved 22nd February, 2017. $7.31 \mathrm{pm}$.

[2] J. Thongplang, "Particulate matters: why monitor PM10 and PM2.5", 2015. http://www.aeroqual.com, Retrieved 23rd May, 2017. 2.44pm.

[3] Mokhloss I. Khadem, Grigore Stamatescu, Valentin Syarcin, "Wireless Measurement Node for Dust Sensor Integration". The sixth international conference on sensor technologies and applications. SENSORCOMM 2012: Faculty of Automatic control and computer, Rome, Italy.

[4] Peter Stacey, Andrew Thorpe \& Paul Robert, "Health and Safety Executive (HSE), Levels of Respirable Dust and Respirable crystalline silica at construction sites". Harpur Hill, Buxton, Derbyshire, 2011.

[5] Technical Fact Sheet: Air Quality-Dust Monitoring. http://www.edonsw.org.au/legal_advice. Retrieved 23rd February, 2017. 9.28pm

[6] T.C. Chineke and I.U. Chiemeka,, "Harmattan Particulate Concentration and Health Impacts in Sub-Sahara Africa". Africa Physical Reviews 3:00-18, 2009.

[7] T. Geiling, S. Leopold, Y. Cheighen and M. Hoffmann, "Fine Dust Measurement with Electrical fields concepts for a capacitive setup. Micromechanical systems group". IMN MacroNano®, Ilmenau University of Technology, Germany, 2011. 